\title{
Doctors need education on prescribing opioids
}

$\mathrm{T}$ he Canadian Medical Protective Association (CMPA) is committed to curbing practices that have led to the opioid abuse crisis. That crisis is largely due to a spike in opioid overdose deaths connected with the street trade in drugs such as fentanyl. But prescribing practices are also implicated.

"I think it is on everybody's radar right now." said Dr. Gordon Wallace, managing director for safe medical care for CMPA, a not-for-profit medical mutual defence organization. All physicians want to find the "sweet spot" for pain relief without adverse risks, but need more education and support, he added

Doctors write 53 opioid prescriptions for every 100 people in Canada, according to numbers compiled for The Globe and Mail by IMS Brogan, which tracks pharmaceutical sales. The Globe reports that there are an estimated 2000 opioidrelated deaths in Canada annually.

Physicians must fundamentally change their approach to when opioids should be prescribed, in what dose and for how long, a panel of experts told the CMPA's annual meeting Aug. 24.

Attendees heard of the case of a 14-year-old boy with infectious mononucleosis who was prescribed fentanyl via transdermal patch to relieve difficulty in swallowing due to a sore throat. The pharmacist questioned the $25 \mu \mathrm{g} /$ hour dosage but did not call the doctor, instead advising the mother to monitor her child closely. She did until the boy went to sleep. The next morning, he could not be revived. The coroner ruled the cause of death was respiratory arrest secondary to fentanyl use.

Professional recognition of the crisis is long overdue, Wallace said in an interview. The CMPA stepped up its involvement following a study of 151 opioid-related, medical-legal cases it handled between 2010 and 2015 .

The CMPA would not provide information on the costs of liability payouts or physician sanctions from the reviewed files, but spokeswoman Isabelle Des Chênes said there were generally more unfavourable outcomes for doctors in opioid complaints than in other CMPA cases.

The 151 civil suits and complaints

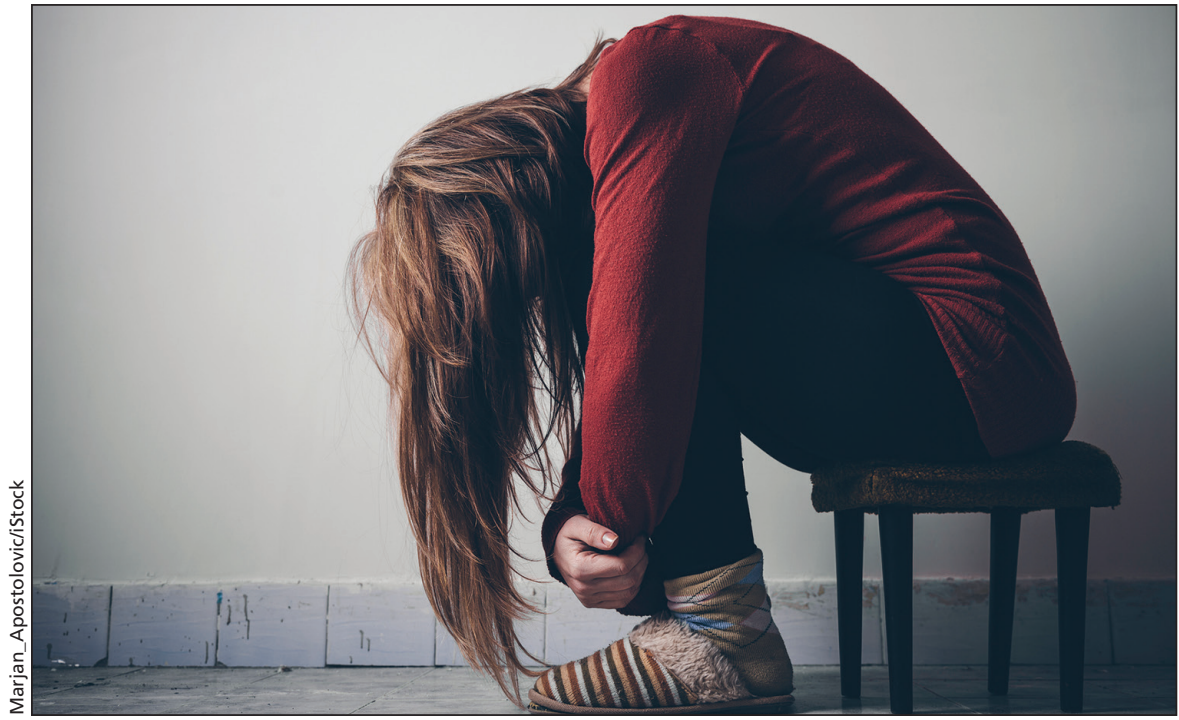

Doctors write 53 opioid prescriptions for every 100 people in Canada.

to professional colleges and hospitals revealed three main areas of concern, Wallace said.

First were shortcomings in assessing when opioids should be prescribed. Canada ranks second only to the United States in per capita opioid consumption, far ahead of Europe and Australia/New Zealand.

The second problem involved doctors prescribing opioids with other drugs, particularly benzodiazepines, exacerbating the risk of respiratory failure.

The third issue is the challenge doctors have in identifying drug-seeking patients who don't have medical conditions that justify opioid use. There needs to be better communication among pharmacists and prescribers to counter these requests, said Wallace.

British Columbia's PharmaNet database was held up as a model for tackling abuse. It records all patient prescriptions, making it easier to flag patients "shopping" for prescriptions and so-called "refill slippage," when patients claim they have lost their pills or need more because they're leaving on a trip.

The number of opioid-related complaints in the study was fairly uniform year over year, Wallace said. "But...I think we're going to see more."

The CMPA issued two publications on opioids this year; one outlining the scope of the problem and a guide to prescribing opioids for non-cancer chronic pain. A third, due this fall, is aimed at hospital practitioners.

The opioid crisis is "the worst manmade epidemic in modern medical history," University of Washington research professor Dr. Gary Franklin told attendees at the CMPA session.

When long-acting opioids were introduced two decades ago, they were pitched as safe, effective, non-addictive therapy for chronic pain, said Franklin, an expert on workers' compensation. They turned out to be none of those things but "we all drank the juice" about their efficacy.

Studies suggest there's no long-term benefit from using opioids to treat chronic pain, said Franklin. Meanwhile, dependency can develop in as little as 30 days; after 90 days, a patient may never come off them again. Franklin recommended opioids be limited to short-term use for acute pain. The rule should be "start slow, go low," added Dr. Heidi Oetter, registrar at the College of Physicians and Surgeons of BC.

A "small subset" of doctors is invested in promoting opioids because of relationships with drug companies, a conflict of interest that needs to come out in the open, Wallace added. The CMPA can use its leverage to help doctors "reset the meter." - Steve Mertl, Vancouver, BC

CMAJ 2016. DOI:10.1503/cmaj.109-5322 